\title{
A IMPORTÂNCIA DA FORMAÇÃO DO PROFESSOR DE PORTUGUÊS: FATOR DECISIVO PARA AS ESCOLHAS TEÓRICO- METODOLÓGICAS QUE NORTEARÃO O FAZER DOCENTE NAS AULAS DE LÍNGUA MATERNA
}

\author{
THE IMPORTANCE OF TEACHER TRAINING: DECISIVE FACTOR FOR \\ THEORETICAL-METHODOLOGICAL CHOICES THAT WILL GUIDE \\ TEACHING IN MATERNAL LANGUAGE CLASSES
}

\section{Francisco Walisson Ferreira Dodó ${ }^{1}$ Denise Santos Fernandes ${ }^{2}$}

\begin{abstract}
RESUMO: Apresentam-se como questão básica deste trabalho a preocupação e os cuidados que se devem ter com a formação dos professores de língua materna. Assim, este artigo tem como objetivo, por meio de uma discussão teórico-bibliográfica, suscitar reflexões acerca da formação do professor de Língua Portuguesa para escolher que conceito de língua nortear a preparação de suas aulas e como essa formação repercute nas aulas de língua materna. Baseando-nos nas ideias dos autores Irandé Antunes (2003,2007), Oliveira (2010), Travaglia (2008), Neves (1991), Possenti (2006), Dik (1978), Nichols (1984), Halliday (1985), Ilari (1992), Givón (1995) e Neves (1997). A discussão permitiu-nos evidenciar que as aulas de Língua Portuguesa só têm sentido quando são vistas na perspectiva de ampliação e desenvolvimento das habilidades linguísticocomunicativas dos alunos, exigindo, portanto, boa preparação dos docentes para poderem ministrar e conduzir as aulas de Português de forma crítica, produtiva e significativa.

Palavras-chave: Formação de Professor; Ensino de Língua Materna; Gramática Tradicional; Gramática Funcional.
\end{abstract}

ABSTRACT: The basic question of this work is the concern and care that should be taken with the training of mother tongue teachers. Thus, this article aims, through a theoreticalbibliographical discussion, to elicit reflections about the formation of the Portuguese Language teacher to choose which language concept to guide the preparation of their classes and how this formation has repercussions in the mother tongue classes. Based on the ideas of authors Irandé Antunes (2003,2007), Oliveira (2010), Travaglia (2008), Neves (1991), Possenti (2006), Dik (1978), Nichols (1984), Halliday Ilari (1992), Givón (1995) and Neves (1997). The discussion allowed us to point out that Portuguese language classes only make sense when viewed from the perspective of expanding and developing the linguistic-communicative skills of the students, thus requiring good preparation of the teachers to be able to teach and conduct Portuguese language classes critical, productive and meaningful way.

Keywords: Teacher Training; Mother Language Teaching; Traditional Grammar; Functional Grammar.

\section{Introdução}

O interesse por esta pesquisa surgiu a partir de inúmeros questionamentos levantados no

\footnotetext{
${ }^{1}$ Doutorando em Linguística - PPGL/UFC. E-mail: walissondodo@hotmail.com

${ }^{2}$ Graduada em Pedagogia - FAK. Licenciada em Letras Inglês - FAK. Professora de Língua Portuguesa da EEEP José Maria Falcão. E-mail: dnisefernandes@gmail.com
} 
ano de 2016 no período de seleção do livro didático de língua portuguesa na escola estadual $^{3}$ onde lecionamos. Nossas discussões fizeram-nos chegar a conclusão de que não basta o livro didático obedecer aos critérios exigidos pelo Programa Nacional do Livro Didático - PNLD - para que possa ser escolhido. Entendemos que, para o alcance dos objetivos das aulas de língua portuguesa, é preciso também considerar não somente os materiais didáticos que serão levados para sala de aula, mas também a formação do professor e com quais conceitos de língua ele trabalha em sala e de que forma esses conceitos são abordados. O objetivo deste artigo é, pois, levantar reflexões acerca da importância da formação do professor e de como ele aborda a língua em sala de aula, para que analisemos como tais abordagens podem repercutir na significância das aulas de português para a vida dos alunos.

Além disso, consideramos este trabalho relevante, embora saibamos que já há muitas outras pesquisas sobre o tema, porque estão sendo levantadas questões e reflexões de professores em exercício de sua função, isto é, que estão no "chão da escola"; e já que nesta pesquisa estamos considerando a importância da formação docente para ministrar as aulas de língua materna, acreditamos ainda que o professor também precisa sentir-se um pesquisador, para assim poder preparar suas aulas, selecionar seu material didático, etc., a fim de garantir um ensino mais consistente e produtivo da língua.

\section{Fundamentação teórica}

Muito se tem falado em um ensino de língua materna pautado em teorias capazes de conferir às aulas de Português uma abordagem mais crítica, reflexiva e funcional da língua(gem) em sala de aula. Assim, essa perspectiva defende que as aulas de Língua Portuguesa favoreçam um espaço que se justifique "prioritariamente pelo objetivo de desenvolver a competência comunicativa dos usuários da língua (falante, escritor/ouvinte, leitor), isto é, a capacidade do usuário de empregar adequadamente a língua nas diversas situações de comunicação" (TRAVAGLIA, 2008, p. 17). Ou seja, oportunizando aos estudantes a prática da produção e recepção de textos que exigirão certas estratégias na sala de aula inspiradas em abordagens que trabalham com a língua "viva", portanto, com a língua em seu funcionamento, em seu uso.

Conceber o estudo da língua por esse viés traz à tona inúmeros questionamentos a respeito de como deve ser a postura adotada pelo professor diante ao ensino de línguas, bem como deve ser sua formação e os impactos disso na preparação das aulas de Língua Portuguesa. Por exemplo, a escola tem se preocupado em oferecer um estudo acerca da língua(gem), tratando-a de maneira palpável e privilegiando-a de forma mais ampla e funcional? (ANTUNES, 2007) A prática docente tem colaborado eficazmente na construção dessa outra escola possível e com o desenvolvimento e ampliação das competências linguísticas dos nossos alunos? Que teorias linguísticas estão sendo levadas - se é que está sendo levada alguma - à sala de aula, a fim de fundamentar e nortear o fazer docente no que diz respeito à preparação e ao modo de conduzir as aulas de língua materna? Baseados nesses questionamentos, queremos propor uma reflexão sobre as contribuições advindas da formação teórico-metodológica do professor para uma prática mais contextualizada do ensino de língua na escola e, desse modo, reconsiderar o ensino de língua materna de uma maneira mais eficaz, levando em conta as situações reais de uso da linguagem nos diferentes processos de comunicação. Ressalte-se que nenhuma prática pedagógica deve ser neutra ou aleatória; que as decisões e escolhas feitas pelo professor no planejamento de suas aulas de Língua Portuguesa devem ser (re)pensadas, que sejam enveredadas por ideias que trabalhem a linguagem em uso, a língua a serviço da comunicação.

Dessa maneira, o professor de língua materna, em seu fazer docente, precisa:

\footnotetext{
3 Trabalhamos na Escola Estadual de Educação Profissional José Maria Falcão, que fica situada no município de Pacajus-CE.
} 
(...) considerar a dimensão social e política do ensino da língua, ou o ensino da língua como meio e possibilidade de a escola atuar na formação, cada vez mais consciente e participativa; (...) compreender como o ensino de línguas - línguas que marcam a identidade cultural de um povo - pode favorecer a formação do sujeito para a cidadania (ANTUNES, 2009, p.33).

Em outras palavras, o trabalho com a língua em sala de aula deve objetivar o alcance de um ensino de língua materna aplicável e de fato eficiente, que só se tornará possível - e é possível quando professores e toda a escola perceberem que uma prática docente bem planejada e arquitetada confere às aulas de Língua Portuguesa verdadeira relevância, consistência e credibilidade, possibilitando aos alunos os possíveis e mais variados manuseios da língua.

Tal finalidade ratifica aquilo defendido por Antunes, ao afirmar que "não pode haver uma prática eficiente sem fundamentação num corpo de princípios teóricos sólidos e objetivos" (ANTUNES, 2003, p. 40), uma vez que toda prática de sala de aula só terá significado e gerará bons frutos, se o professor, responsavelmente, deixar-se ser guiado e embasado teoricamente, sempre, por alternativas lúcidas, coerentes e, portanto, possibilitadoras de um uso consciente e responsável da língua.

Tornar produtivas as aulas de língua materna e associá-las a teorias que sustentam e defendem um ensino de língua adequado e eficaz é uma tarefa necessária e cautelosa, pois:

(...) o professor precisa se conscientizar da necessidade de dominar determinados conhecimentos teóricos para poder tomar decisões fundamentadas no que diz respeito ao planejamento das aulas, à escolha das atividades a serem realizadas em sala de aula, ao gerenciamento das aulas e ao processo de avaliação. Sua prática pedagógica precisa estar explicitamente baseada em arcabouços teóricos que fundamentem e justifiquem suas ações, suas decisões (OLIVEIRA, 2010, p. 23-24).

Desse modo, de acordo com Oliveira (2010), é imprescindível, pois, que o fazer docente, necessariamente, esteja respaldado e seja orientado à luz de referenciais teóricos que tornem as aulas de Língua Portuguesa significativas e, verdadeiramente, propícias ao desenvolvimento e formação dos nossos alunos, quanto ao uso da língua; urgem, portanto, a relevância e a preocupação que se deve ter com a formação do professor de Português, incumbindo-lhe a responsabilidade de centrar-se "(...) no objetivo de desenvolvimento e sistematização da linguagem interiorizada pelo aluno, incentivando a verbalização da mesma e o domínio de outras utilizadas em diferentes esferas sociais" (PCN, 1999, p. 139).

Essa perspectiva de ver a língua faz-nos levantar questionamentos acerca do porquê da existência do ensino de língua materna nas escolas e de suas contribuições no uso prático na vida dos estudantes; sabe-se que são muitas as reflexões levantadas acerca de como vêm acontecendo as aulas de língua materna, como e qual deve ser o papel do professor à frente da disciplina de Língua Portuguesa.

Por isso, é preciso que seja analisado: se a escola tem contribuído, positivamente, com a formação discente frente ao uso da língua nas práticas sociais; se o professor de língua materna está procurando "trazer para o seu entendimento princípios teóricos, conscientes e bem fundamentados, a fim de explicitar teorias geradoras de reflexão e capazes de promover uma intervenção mais significativa na escola" (ANTUNES, 2009, p. 14); e se os professores estão se preocupando em preparar, bem e eficientemente, suas aulas de língua materna, visando justificar o ensino de Português como disciplina importante no currículo escolar para o desenvolvimento e o aprimoramento das habilidades linguísticas dos alunos.

Esses apontamentos feitos a respeito das práticas pedagógicas que vêm sendo aplicadas em sala de aula tornam evidente a relevância de um ensino de língua materna norteado por uma abordagem da língua de maneira significativa e funcional e a urgência de uma escola que visa a 
uma boa formação linguística de seus estudantes.

Desse modo, esses objetivos, para serem alcançados, dependerão muito diretamente da ação-reflexão do professor, do seu compromisso e responsabilidade com o modo de ministrar suas aulas e, é claro, do seu referencial teórico eleito para guiar e preparar suas aulas.

E, em se tratando das aulas de língua materna, é necessário, para o alcance de tais finalidades, que o professor saiba: “(...) o que é língua” (OLIVEIRA, 2010, p. 24) e que abordagem conceitual de língua ele elege para o trabalho com a linguagem no contexto de ensino e aprendizagem.

Isto é, para conseguirmos enxergar a realização do verdadeiro propósito que deve ser alcançado nas aulas de Língua Portuguesa, irá depender das concepções de língua e de suas abordagens pedagógicas escolhidas para embasar e orientar o professor de Português no dia a dia na sala de aula, já que "(...) todo professor, de qualquer disciplina, precisa de um mínimo de teorias para sustentar suas ações em sala de aula, para tomar decisões pedagógicas consistentes (...)" (OLIVEIRA, 2010, p. 15).

É cabível, portanto, o seguinte questionamento: por que o sucesso das aulas de língua materna está intrinsecamente relacionado a uma formação docente sólida e consciente? Neves (1991), em seu livro Gramática na escola, vem ressaltar que ainda é muito pouca a preocupação dos professores quanto à busca de um referencial teórico que possa nortear suas aulas (NEVES, 1991), tornando-as, verdadeiramente, atrativas, produtivas e mediadoras para o alcance do desenvolvimento linguístico dos alunos. Assim, “(...) se nossa prática de professores se afasta do ideal é porque nos falta (...) um aprofundamento teórico acerca de como funciona o fenômeno da linguagem humana" (ANTUNES, 2003, p. 40).

Dessa maneira, faz-se necessário fortalecer a ideia de que os rumos que as nossas aulas de língua materna terão, poderão ser positivos ou negativos; isso vai depender de como o professor abordará o conceito de língua e das escolhas dos métodos de ensino para conduzir a prática e o exercício da linguagem na sala de aula.

Sabe-se que há várias teorias e abordagens da língua. Neste artigo, gostaríamos de discutir duas tendências teóricas, a fim de contrapô-las: os estudos estruturalistas da língua e os estudos funcionalistas.

Em seu Curso de Linguística Geral, Saussure (1975), afirma que a "língua é um sistema de valores que se opõem uns aos outros. Ela está depositada como produto social na mente de cada falante de uma comunidade e possui homogeneidade. Por isso é o objeto da linguística propriamente dita" (SAUSSURE, 1975, p. 38). Essa óptica considera, pois, a língua como um sistema organizado, como um conjunto de regras internalizadas estruturalmente organizadas. Assim, a língua, é considerada a gramática de uma mesma comunidade de falantes. Além disso, Saussure afirma que "a linguística tem por único e verdadeiro objeto a língua considerada em si mesma e por si mesma" (SAUSSURE, 1975, p. 38).

Essa visão que afirma que "a língua é um sistema cujas partes podem e devem ser consideradas em sua solidariedade sincrônica" (SAUSSURE, 1975, p.38) acabou contribuindo com o fortalecimento de ideias equivocadas quanto ao conceito de gramática e os tipos de gramática. Vale ressaltar que, quando Saussure elegeu a língua como objeto único da Linguística, ele reconhecia que o uso dessa estrutura, que é a gramática do falante, deveria servir a um propósito maior, a comunicação, entretanto o autor tinha outros objetivos de análise, por isso exclui a fala dos seus estudos, mas esse posicionamento, por muito tempo e até os dias de hoje, contribuiu fortemente para um ensino de gramática esvaziado no estudo da língua pela língua, portanto da estrutura pela estrutura.

Ainda é bastante comum depararmo-nos com exercícios gramaticais pedindo ao aluno que apenas identifique, classifique e aprendam as nomenclaturas gramaticais em detrimento da aplicação dos conhecimentos gramaticais que deveriam ser trabalhados a fim de cumprir o propósito do ensino de língua materna: a aprendizagem dos conhecimentos linguísticos, portanto, da gra- 
mática para o desenvolvimento das habilidades linguísticas: o domínio da leitura e compreensão textual e o domínio da escrita para a produção textual (ANTUNES, 2003). Em contrapartida, teceremos como os pressupostos teóricos do funcionalismo entendem a língua e mostraremos de que modo essa visão pode contribuir para o ensino de língua. Para isso, trazemos os estudos feitos por Dik (1978), Nichols (1984), Halliday (1985), Ilari (1992), Givón (1995), e Neves (1997).

Entende-se, por gramática funcional, a geração de (...) "uma teoria da organização gramatical das línguas naturais que procura integrar-se em uma teoria global da interação social" (NEVES, 1997, p. 15). Desse modo, de acordo com Ilari (1995), a língua é entendida pelo Funcionalismo como um sistema que é utilizado para cumprir determinada finalidade; a língua tem, pois, como finalidade principal possibilitar a interação social e a comunicação do homem, (Dik, 1978). Assim, para Dik (1978), língua natural deve ser entendida como instrumento de interação social, que não existe por si só, uma vez que a língua natural existe porque seu uso concreto e real possibilita essa interação, que cria a principal função de uma língua natural - a comunicação entre os falantes e usuários desse código, por isso a língua deve ser concebida como um evento de interação comunicativa, e não como um sistema autônomo, sem considerar seu conceito de uso; a língua deve associar-se tanto a processos mentais quanto a interações socioculturais, uma vez que ela está para a comunicação, Givón (1995).

Nichols (1984), em convergência com Givón, defende que a gramática funcional, embora estude as estruturas gramaticais da língua, ela considera a análise da situação comunicativa, representada pelas finalidades dos eventos de linguagem, pelos participantes desse evento e por seu contexto discursivo.

A gramática, sob esse ponto de vista, está a serviço, segundo Dik (1989), à interação verbal, criando uma forma estruturada de cooperação, já que essa interação é regida por regras, normas e convenções. $\mathrm{Na}$ interação verbal, os usuários interactantes da língua se utilizam das expressões linguisticas, que, para Dik (1989a), consideram-se dois tipos de regras: as semântico-sintáticas, morfológicas e fonológicas, que governam e organizam as expressões linguísticas, e os fatores pragmáticos, que constituem as regras que governam os padrões de interação verbal onde essas expressões linguísticas (a gramática) são utilizadas.

Desse modo, percebe-se a influência que o contexto comunicativo pode exercer no uso da língua. Os teóricos Dik (1978) e Halliday (1985) sobre a relação entre língua e uso da língua, especificada no quadro 1, defendem que:

Quadro 1 - Relação entre uso e língua

\begin{tabular}{|l|l|}
\hline \multicolumn{1}{|c|}{ Dik (1978) } & \multicolumn{1}{c|}{ Halliday (1985) } \\
\hline as expressões linguísticas, os textos, portanto, só podem & a língua deve ser compreendida dentro do texto ou do \\
ser compreendidos se analisados em funcionamento & discurso. Logo, assim como Dik, Halliday reconhece que \\
dentro de seus contextos comunicativos. & a língua - atividades textuais - só existe, porque são pro- \\
duzidas em um determinado contexto comunicativo.
\end{tabular}

Analisemos, a seguir, a figura 1 que exemplifica bem o conceito de língua proposto pelo funcionalismo. 


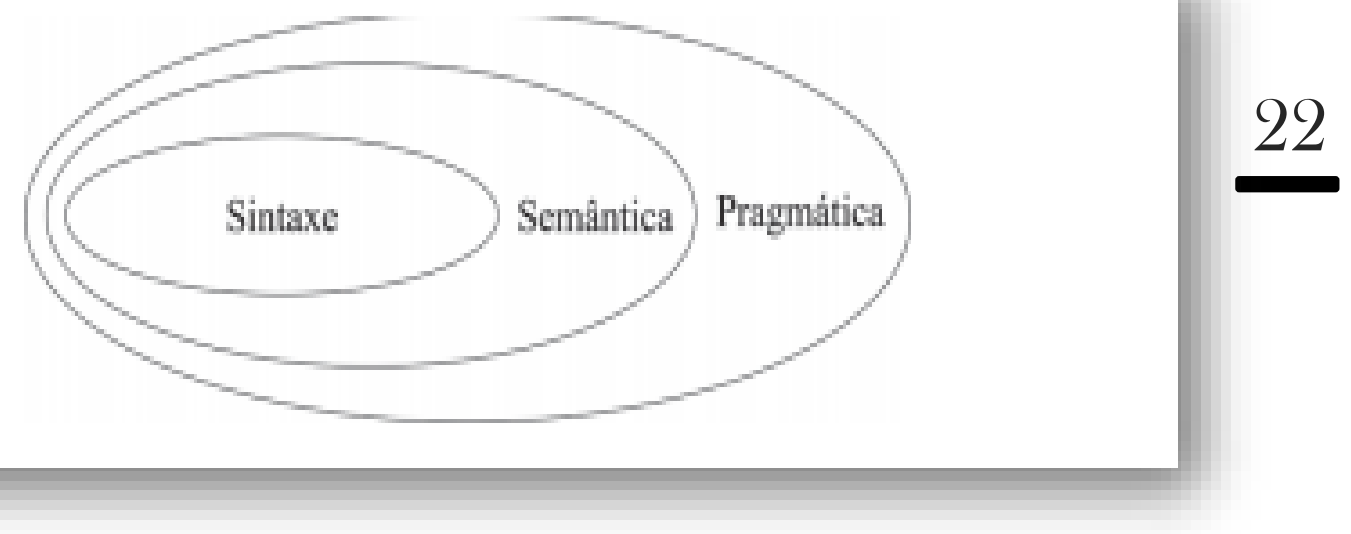

Fonte: Sperança-Criscuolo (2014)

Considerado esse viés representado no quadro de concepção da língua, a gramática funcionalista vai defender que a língua (que é a própria gramática, a sintaxe) deve estar para a função da comunicação, isto é, seu uso (a pragmática) vai agir nas estruturas linguísticas, como elas produzirão sentido (a semântica). Logo, a gramática só fará sentido se for adequadamente usada em seu contexto de uso. E, uma vez que a interação e a comunicação se dão pelos gêneros de texto, o ensino da gramática na escola deve favorecer o desenvolvimento das habilidades linguísticocomunicativas do aluno. O ensino de gramática deve, portanto, oportunizar a aprendizagem do uso da língua para a produção e recepção de textos.

Tendo mostrado como essas duas teorias abordam o funcionamento da língua, destacam-se importantes implicações que repercutirão no alcance ou não dos objetivos do ensino de língua materna, porque, se por um lado reconhecemos a importância de dominar as estruturas linguísticas, não podemos esquecer que esse conhecimento estrutural da língua só fará sentido se aplicado adequadamente na produção de texto em seus contextos de comunicação.

Nesse sentido, o professor é peça fundamental no jogo para o sucesso das aulas, pois serão suas decisões e escolhas teóricas que vão garantir ou não a aprendizagem efetiva e produtiva da gramática. Vê-se, portanto, que é necessária uma prática docente reflexiva e responsável, se quisermos alcançar os objetivos de se ensinar a língua e as suas possibilidades de uso, de fomentar uma formação de usuários da língua que a compreendam, criticamente, e usem-na de forma cônscia, participativa e engajada nas diversas esferas sociais.

Então, que práticas pedagógicas e quais conceitos acerca da língua o professor precisa dominar e levar às suas aulas, a fim de torná-las significativas e relevantes? Ou seja, por que se torna decisivo para o alcance de boas aulas de Língua Portuguesa que o professor domine e pratique conscientemente conceitos, como: o que é língua? Que abordagens linguísticas existem e como aplicá-las em sala de aula ao trabalhar a linguagem?

Ora, essas são perguntas que constituem a base do referencial teórico que o professor de Português precisa conhecer e usar em suas aulas. Isto é, são esses questionamentos que irão apontar caminhos por que o professor deverá trilhar com a finalidade de tornar as aulas de língua materna um verdadeiro encontro propiciador do desenvolvimento das habilidades linguísticas dos nossos alunos, uma vez que é indispensável que:

(...) o professor garanta ao aluno a oportunidade de enfrentar o desafio da leitura, da escrita, da escuta, da fala (do convencional cotidiano à fala formal), (...). Só assim ele há de chegar à experiência comunicativa inteiramente assumida, com a autoconfiança de que somos capazes de exercer, também pelo linguístico, a cidadania que nos cabe por pleno direito (ANTUNES, 2003, p166). 
Assim, tal finalidade poderá ser cumprida se a escola repensar sua prática de ensino em relação à abordagem da linguagem, aderindo a novas perspectivas de língua e de ensino da língua no contexto escolar (POSSENTI, 2006, p. 32-33; in GERALDI, 2006). Por isso, acreditamos que, em relação à escolha do conceito de língua a ser aplicado como bússola nas aulas de Português, devemos eleger a teoria que vê a língua “(...) situada no emaranhado das relações humanas, nas quais o aluno está mergulhado. Não a língua divorciada do contexto social vivido." (PCN, 1999, p. 141).

Desse modo, fica evidente a urgência de um ensino de língua que visa ao desenvolvimento linguístico-comunicativo dos estudantes, exigindo dos mesmos uma prática frequente de leitura e produção escrita, uma prática de uso e de interpretação de todos os tipos de linguagem, a fim de possibilitá-los o uso efíciente e adequado da língua, dominando e (re)criando novas estratégias de comunicação.

Esse pensamento solidifica, comprova e justifica cada vez mais a necessidade de uma boa formação do professor de língua materna e de seu compromisso com os estudos da linguagem. Partindo desse princípio, podemos afirmar que é prudente - e também uma postura certeira elegermos o conceito de língua defendido pela gramática funcionalista, para nos auxiliar na abordagem da linguagem nas aulas de Língua Portuguesa, uma vez que tal teoria nos permitiria alcançar "(...) o objetivo último do ensino do português: a ampliação da competência comunicativa do aluno para falar, ouvir, ler e escrever textos fluentes, adequados e socialmente relevantes" (ANTUNES, 2003, p. 122).

Essa perspectiva interacionista confere ao aluno o poder de ser autônomo no processo de aprendizagem e o vê, portanto, como um ser ativo; também como um facilitador do conhecimento (OLIVEIRA, 2010, p. 28-29), aprenda a ver além das estruturas linguísticas, uma vez que:

saber português significa não apenas ter o domínio inconsciente das estruturas gramaticais, das regras que regem essas estruturas e do léxico, mas também ter domínio de normas socioculturais de comportamento que possibilitam interagir uns com os outros (OLIVEIRA, 2010, p. 40).

Dessa maneira, o aluno passa a ter voz e vez na sala de aula, suas ideias e identidade sociocultural ganham destaque; o aluno, agora, precisa ser estimulado e instigado à ampliação dos seus conhecimentos - incluindo suas habilidades linguístico-comunicativas - e à busca de novos saberes.

Por isso, a urgência de o professor de língua materna perceber-se também como um pesquisador, a fim de posicionar-se criticamente frente às suas escolhas teóricas que o nortearão no ensino de língua, pois é nesse contexto que se considera a relevância do ensino de língua materna, de fato, significativo aos estudantes, pois respaldar a formação do professor na perspectiva sociointeracionista da língua conferirá à escola a responsabilidade de estar formando e preparando seus alunos a fazerem lúcido, responsável e adequadamente, um exímio uso da língua nas esferas de comunicação. Ou seja, fica como dever e compromisso do professor de língua materna orientar, "ajudar o estudante a aprender a se comportar linguisticamente em diversas situações de interação social", uma vez que "ensina-se português a brasileiros" é para "ajudá-los a desenvolver sua competência comunicativa" (OLIVEIRA, 2010, p. 43) - o objetivo principal das aulas de Língua Portuguesa.

\section{Metodologia}

Para a construção deste artigo, propomos fazer uma discussão teórico-epistemológica sobre a formação do professor baseados nos estudos de Irandé Antunes (2003,2007), Oliveira (2010), Travaglia (2008), Neves (1991), Possenti (2006). Na seção de análise de dados, intitulada 
"Conceito de língua e ensino de língua materna: repercussões no ensino", propomos um quadro comparativo, analisando uma atividade sobre concordância verbal proposta por dois livros didáticos; um que defende o conceito de língua à luz da gramática funcionalista (Ser Protagonista: Lingua Portuguesa) e outro (Gramática da Lingua Portuguesa), que aborda o conceito de língua de acordo com a gramática tradicional afim de elucidar o quanto essa formação do professor é decisiva para que as aulas de língua portuguesa sejam efetivados. Com base nas análises das atividades, pretendemos mostrar como essas duas teorias repercutem na maneira de abordar a linguagem em sala de aula. Os livros didáticos foram escolhidos de modo a explanar que o material de apoio, em consonância com teoria eleita pelo docente, repercute na prática de sala de aula. A concordância verbal no português brasileiro inclui-se no conjunto dos fenômenos gramaticais sujeitos à variação. Por isso, foi usado como recorte em nossa análise, haja vista que a concordância verbal é governada por condições de natureza funcional e estrutural.

\subsection{Conceito de língua e ensino de língua materna: repercussões da formação do professor na prática docente}

A propósito dessas observações, não cabe, no ensino de Língua portuguesa - LP, meramente atuar no sentido de os alunos desenvolverem seu domínio das atividades de sala e escrita. Apenso a esse trabalho (que é a parte fundamental do ensino), urge desempenhar sempre uma ação reflexiva sobre a própria língua, enquadrando as atividades verbais e o pensar sobre elas. Passemos a analisar o conteúdo Concordancia Verbal e Nominal a luz de um Livro Didático - LD que adota a gramática funcionalista e outro na gramática estruturalista; para discorremos o quanto são importantes à formação continuada, à postura nas aulas de LP e à pesquisa do professor para a eficácia da metodologia.

Os livros didáticos foram escolhidos de modo a explanar que o material de apoio, em consonância com teoria eleita pelo docente, repercute na prática de sala de aula. A concordância verbal no português brasileiro inclui-se no conjunto dos fenômenos gramaticais sujeitos à variação. Por isso, foi usado como recorte em nossa análise, haja vista que a concordância verbal é governada por condições de natureza funcional e estrutural. Serão utilizados para a análise os LD: Ser Protagonista: Lingua Portuguesa e Gramática da Lingua Portuguesa (Vide quadro 2).

Quadro2 - Livros analisados

\begin{tabular}{|l|l|}
\hline \multicolumn{1}{|c|}{ LD 1 } & \multicolumn{1}{|c|}{ LD2 } \\
\hline Ser protagonista: Língua Portuguesa & Gramática da Língua Portuguesa. Pasquale Cipro Neto, \\
$3^{\circ}$ Ano: Ensino Médio / Ricardo Gonçalves Barreto [et & Ulisses Infante. SP: Scipione, 2003. \\
al.] Org. Edições SM; 3 ${ }^{\text {a Ed. SP: Edições SM, 2016. }}$ & \\
\hline
\end{tabular}

Em consonância com as Orientações Curriculares para Ensino Médio - OCEM, a coleção Ser Protagonista dispõe em primeiro plano a interação entre sujeitos de modo a garantir a reflexão sobre linguagem e língua. Assume-se, então, uma exposição do funcionamento da língua tendo como objeto - privilegiadamente - as variedades urbanas de prestigio e a norma culta. O LD adota uma postura crítica à Norma Gramática Brasileira - NGB - questionando-a através da construção da metalinguagem para se referir aos fenômenos linguísticos, investigar a produção de efeitos de sentido da língua.

Já no livro "Gramática da Lingua Portuguesa" de Cipro Neto e do professor Ulisses Infante, os autores afirmam que: "a gramática é mecanismo fundamental para o domínio do padrão culto da língua. A Gramática, e não as gramatiquices. A Gramática que mostra o lado lógico, inteligente, racional dos processos linguísticos" (NETO \& INFANTE, 2003, p. 25). Percebe-se, que diferentemente da abordagem funcionalista, pode-se inferir que, saber gramática, para eles, é saber falar e escrever bem; os autores consideram, assim, como "correto" apenas a gramática tradicional-

https://periodicos.unifap.br/index.php/letras

Macapá, v. 9, n. 3, $2^{\circ}$ sem., 2019 
normativa; o próprio título do livro nos leva a essa ideia "Gramática da Lingua Portuguesa", desconsiderando e excluindo as variantes da língua.

Figura 2

\section{Prática de linguagem}

1. Leia a tira e a definição de dicionário apresentadas a seguir.
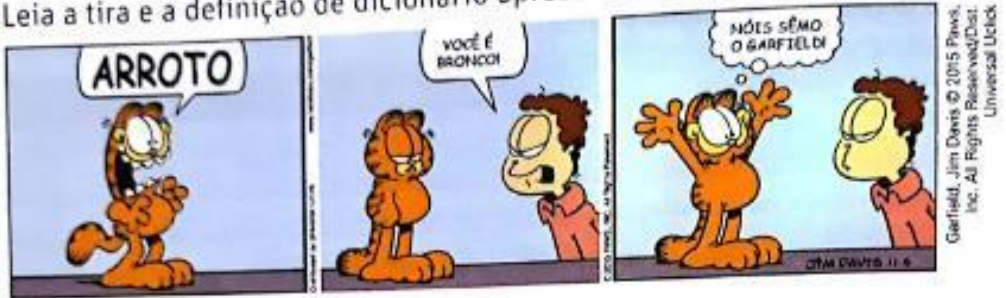

Davs, Jim. Garficld

bronco adj.s.m. [...] 3. que ou quem é ignorante, grosseiro 4. que ou quem é dado a ser áspero no trato 5 . que ou quem demonstra pouca inteligência; obtuso 6 . que ou quem carece de graciosidade; desajeitado, tosco.

Hownss, Antonio; Vuur, Mauro de Salles; Franco, Francisco Manoel de Mello (Dir.). Diclonánio Houaiss eletrónico da lingua portuguesa. Rio de Janciro: Objetiva, 2009, 1 CD-ROM.

a) Por que Jon diz que Garfield é bronco?

b) Ao chamar Garfield de bronco, a qual acepçăo da palavra Jon está se referindo?

c) Quando responde "nóis sêmo o Garfield", o gato manifesta uma acepção de bronco diferente da de Jon. Qual?

d) Tendo em vista o que você já aprendeu sobre concordância, variação linguística, gramaticalidade e preconceito linguístico, explique a resposta de Garfield e o motivo pelo qual sua acepçăo de bronco é inadequada.

A atividade Prática de Linguagem (figura 2) leva os alunos a praticarem o conceito de concordância trabalhado através da investigação significativa de sua relação com a produção de efeito de sentido. Visa avaliar a situação de uso da língua, portanto, considera o contexto de produção, para adotar ou não a concordância como prevista pela NGB.

A questão é elaborada a partir da tirinha do Garfield, personagem de Jim Davis, em que ele arrota bem alto. No segundo quadrinho, Jon o chama de bronco. Nos itens $a$ e $b$, o aluno é convidado a refletir o porquê que Garfield é bronco e em qual acepção do Houaiss. No item $c$, a resposta do gato (Nóis sêmo o Garfield!) revela que ele entende bronco alguém ignorante ou de pouca inteligência, reproduzindo o falar de uma variedade linguística rotulada, ou seja, de alguém que não sabe usar a concordância de acordo com a gramática normativa. Ao responder o item $\mathrm{d}$, o estudante reflete acerca de concordância, variação linguística, gramaticalidade e preconceito linguístico.

Percebe-se que atividades deste tipo melhoram a compreensão do educando sobre língua, tornando-o um leitor e produtor de texto eficaz. Desse modo, pode-se ressaltar que, a partir da postura adotada pelo professor em pesquisar e investigar o ensino de gramatica, o ensino não resultará em uma metodologia estanque e restritiva. Passemos à análise da atividade proposta pelo segundo livro didático. 


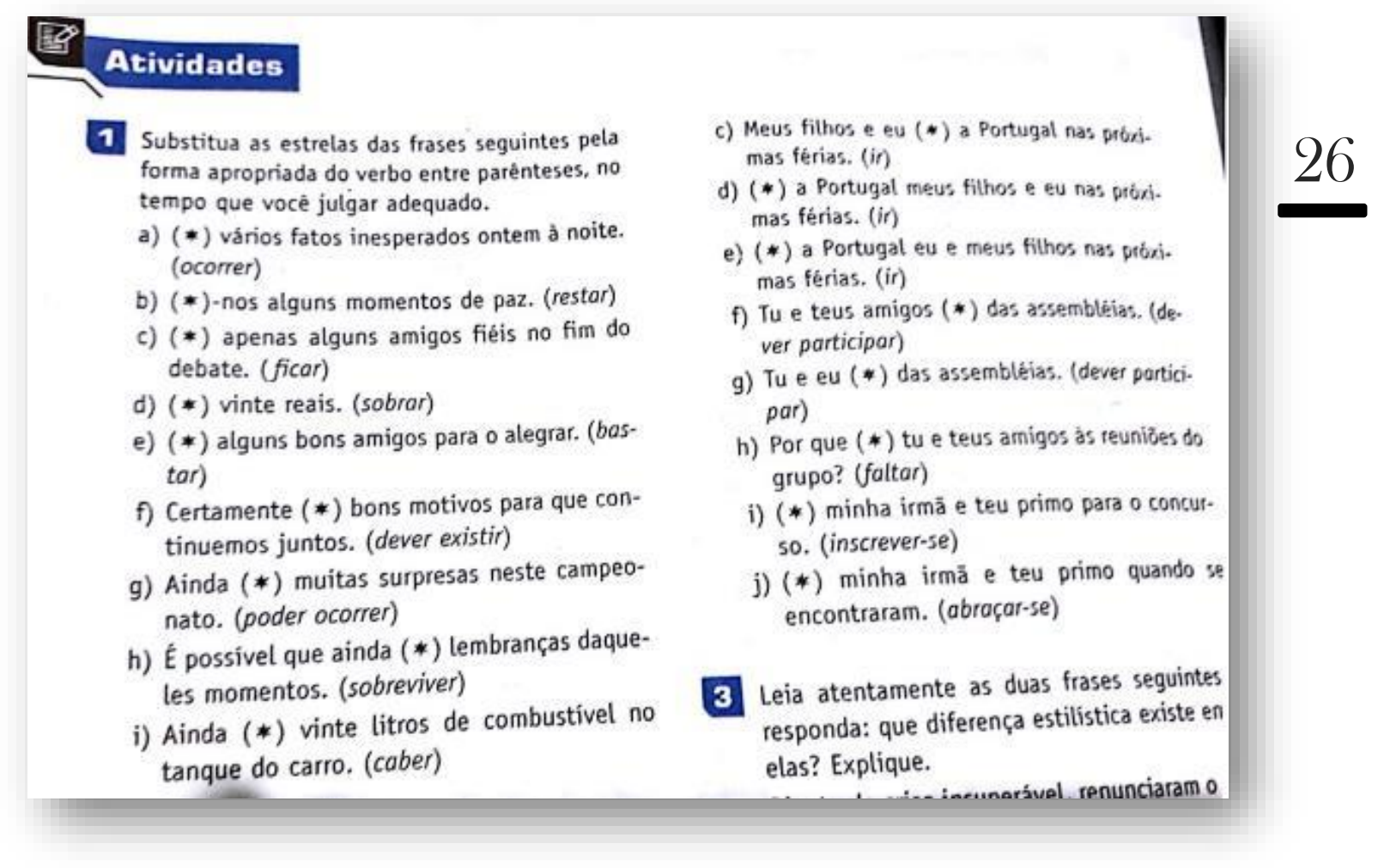

A atividade do LD2 é elaborada a partir de frases soltas que devem ser completadas pelos verbos apropriados, de forma a usar as regras de concordância segundo a NGB. A crítica básica e fundamental à atividade do LD2 (figura 2) recai sobre o atributo excessivamente normativo do trabalho com a linguagem, confundindo o ensino de língua com o ensino de gramática. Essa abordagem não é suficiente. Não há dúvidas de que se deve ensinar gramática normativa nas aulas de LP, embora se saiba perfeitamente que ela em si não ensina ninguém a falar, ler e escrever com precisão (ANTUNES, 2007 P 53).

Salienta-se aqui que o legado gramatical viabiliza uma metalinguagem bastante útil para tratar da língua humana que a própria linguística pouco alterou. Contudo, para aprender a variante mais padronizada e prestigiosa da língua, não é obrigatório saber a nomenclatura gramatical clássica, as definições tradicionais, nem praticar a habitual análise lexical e muito menos a penosa análise sintática. $\mathrm{O}$ aluno pode sim ter acesso a esses conhecimentos linguístico-estruturais da língua (ANTUNES, 2003), entretanto esvaziar o ensino da língua nessa abordagem pouco contribuirá para que o aluno aprenda a usar adequado e produtivamente a língua. Ainda, no LD2 o autor apresenta uma visão estruturalista da gramática, como podemos ver na figura 4: 


\section{Casos de sujeito simples que merecem destaque}

Há muitos casos em que o sujeito simples é constituido de formas que fazem o falante hesitar no momento de estabelecer a concordância com o verbo. Em alguns desses casos, a concordância puramente gramatical é contaminada pelo significado de expressỏes que nos transmitem noção de plural apesar de terem forma de singular ou vice-versa. Por isso, convém analisar com cuidado algumas delas.

a. expressões partitivas - Quando o sujeito é formado por uma expressão partitiva (parte de, uma porção de, o grosso de, metade de, a maioria de; a maior parte de, grande parte de) seguida de um substantivo ou pronome no plural, o verbo pode ficar no singular ou no plural:

A maioria dos jornalistas aprovou / aprovaram a idéia.

Metade dos candidatos não apresentou / apresentaram nenhuma proposta interessante.

468 Gramática da Lingua Portuguesa

Nota-se que há uma valorização muito mais ao trabalho somente com estrutura da língua do que seu uso. Acreditamos que se perde muito com essa valorização excessiva da estrutura pela estrutura, porque deixamos de enriquecer a aula com o uso da língua nos diversos contextos de produção; e já que a gramática está a serviço da comunicação e interação (NEVES, 1997), o trabalho com a gramática deve, portanto, considerar as influências dos contextos de uso para seu uso.

Outro ponto a ser destacado está na frase "...a concordância puramente gramatical é contaminada pelo significado de expressões que nos transmite noção de plural...” que desconsiderada de maneira eloquente a diversidade linguística e reforça pré-conceitos, os fatos da língua e a diversidade sociocultural. A palavra contaminar, segundo o Houaiss, significa "infectar por doença contagiosa. [Figurado] Sujar, enlamear; conspurcar" o que nos leva a perceber que, ao adotarmos uma postura estruturalista, perpetuamos que uma só variante tem muito prestígio social (e constituem aquilo que chamamos de norma padrão), enquanto outras são menos prestigiadas e até ridicularizadas e censuradas, relembramos isso na fala do Garfiled ("Nóis sêmo o Garfield") no LD1 em que essa questão aparece como ponto de partida para discussão.

Cônscio dessa análise, o professor deve abandonar o conformismo e a repetição de doutrina gramatical e ser mais proativo ministrando o conteúdo de forma reflexiva em práxis mais contextualizadas, interdisciplinares, individuais ou coletivas, de sorte que os aprendizes conheçam as variedades da língua através de pesquisas as quais envolvam leitura e produção textual construindo seu próprio conhecimento linguístico.

Assim, um ensino produtivo e significativo pauta-se na relação entre ensino de gramática normativa e contextualização, isto é, (gramática e contexto de uso), sem descartar nomenclaturas, terminologias e regras - as quais são basilares para o desenvolvimento social e cultural dos educandos. E o professor, como mediador desse conhecimento, é peça-chave e, portanto, deve buscar formação continuada, não somente teórica, mas também na prática e no contexto da realidade em que está inserido.

Dessa maneira, o melhor caminho para se atingir o domínio da norma padrão é o contato direto e sistemático com a língua viva, com textos oriundos das mais diversas esferas de comuni- 
cação, por exemplo, dos meios de comunicação social (revistas e jornais) e, também, com os textos literários.

Vale ressaltar que nosso foco não é a sala de aula, tampouco o livro didático. Fizemos essa análise do estruturalismo e do funcionalismo para exemplificar o quanto a formação do professor implica na seleção do material de apoio para a prática docente. Com isso, incitar nos professores uma visão mais crítica acerca de suas práticas pedagógicas, conscientizando-os da importância de repensar a atual abordagem dada ao estudo da Língua Portuguesa, buscando, assim, que o estudo da língua aconteça a partir da interação entre os sujeitos e suas relações nos diferentes processos que envolvem a linguagem.

\section{Considerações finais}

E, assim, baseados nas teorias supracitadas que foram defendidas neste trabalho acerca de como deve ser o trabalho com a linguagem no contexto escolar, a fim de alcançarmos aulas de Português, verdadeiramente, consistentes e promovedoras de reflexão e uso da língua, almejando práticas eficientes e adequadas da linguagem, podemos concluir que as aulas de língua materna precisam ser vistas como um encontro de interação e desenvolvimento das habilidades linguísticas dos alunos.

Almejando ensinar bem a língua, devemos ter bastante clareza sobre isso, não embaralhando o nível estrutural e os valores sociais, entendendo que aqueles que usam variantes desmerecidas não são linguisticamente inferiores. E, concomitantemente, precisamos ter um olhar crítico sobre os índices sociais de valor (positivos ou negativos) que recobrem as variedades linguísticas, para que a norma padrão fique devidamente assentada em meio às demais variedades e não se torne nem restritiva nem excludente.

Fica evidente, pois, a exigência de uma excelente capacitação e formação do professor de língua materna, uma vez que reger e conduzir as aulas de Português é uma tarefa que requer muita responsabilidade e discernimento, pois ao professor de línguas lhe é conferido o compromisso de mediar e orientar um uso da língua de forma atuante e significativa, por isso, responsável.

Enfim, o professor de língua materna está incumbido de conduzir o aluno a também dominar a linguagem - com todas as suas possibilidades de uso - para que possa, eficientemente, pela língua, autoafirmar-se como sujeito que tem voz e que sabe usá-la adequadamente e eficientemente. Portanto, está na hora de nós, professores de língua materna, percebermos a nossa extrema relevância para o sucesso das aulas de Português, comprometendo-nos em ministrar e conduzir nossas aulas fazendo uso de teorias e práticas pedagógicas que, efetivamente, possibilitarão o alcance do objetivo maior do estudo da linguagem na escola: formar cidadãos competentemente preparados para manusear a língua, capaz e adequadamente, em suas mais diversas possibilidades de uso.

\section{Referências}

ANTUNES, I. Muito além da gramática: por um ensino de língua sem pedras no caminho. São Paulo: Parábola Editorial, 2007.

ANTUNES, I. Aula de Português: encontro e interação. São Paulo: Parábola Editorial, 2003.

ANTUNES, Irandé. Lingua, Texto e Ensino: outra escola possível. São Paulo: Parábola Editorial, 2009.

BARRETO, Ricardo Gonçalves [et al]. Ser protagonista: língua portuguesa, $3^{\circ}$ ano: Ensino Médio; obra coletiva concebida, desenvolvida e produzida por Edições SM; 3 ed. São Paulo: Edições SM, 2016.

BRASIL, Ministério da Educação, Secretaria de Educação Média e Tecnológica. Parâmetros Curriculares Nacionais: ensino médio. Brasília: Ministério da Educação, 1999. 
BRASIL. Parâmetros Curriculares Nacionais: Ensino Médio. Brasília: Ministério da Educação, 1999.

CIPRO NETO, Pasquale. INFANTE, Ulisses. Gramática da Lingua Portuguesa. SP: Scipione, 2003.

DICK, C. S. Functional Grammar. Dorderecht-Holanda/Cinnaminson-EUA: Foris Publications, 1978.

GIVÓN, T. Functionalism and Grammar. Amsterdam/Philadelphia: John Benjamin Publishing Company, 1995.

HALLIDAY, M.A.K. An introduction to functional grammar. London: Arnold, 1985.

ILARI, R. Perspectiva funcional da frase portuguesa. $2^{\mathrm{a}}$ ed. Campinas: Editora da UNICAMP, 1992.

NEVES, M. H. M. Gramática na escola. 2 ed. São Paulo: Contexto, 1991; 1997.

NICHOLS, J. Functional Theories of Grammar. Annual Review of Anthropology, v. 43, 97-117: Berkeley, 1984.

OLIVEIRA, L. A. Coisas que todo professor de Português precisa saber: a teoria na prática. São Paulo: Parábola Editorial, 2010.

POSSENTI, S. Sobre o ensino de Português na escola. In: O texto na sala de aula. 4.ed. São Paulo: Ática, 2006.

POSSENTI, S. Por que (não) ensinar gramática na escola. Campinas, São Paulo: Mercado das letras: Associação de Leitura do Brasil, 1996.

SAUSSURE, F. Curso de Linguistica Geral. Organização de Charles Bally e Albert Sechehaye com a colaboração de Albert Riedlinger. Trad. de Antônio Chelini, José Paulo Paes e Izidoro Blikstein. 24a ed. São Paulo: Pensamento-Cultrix, 2002.

TRAVAGLIA, L. C. Gramática e Interação: uma proposta para o ensino de gramática. 12 ed. São Paulo: Cortez, 2008.

Enviado em: 14/09/2018

Aceito em: 10/07/2019 